\title{
IV IV IV
}

التخطيط الاستراتيجى الشخصى

$$
\begin{aligned}
& \text { إعلىاق : } \\
& \text { أ / سماح سلامهة }
\end{aligned}
$$

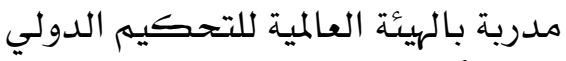

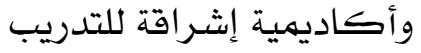





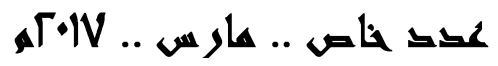

$$
\text { التخطيط الاستراتيجى الشخصى سلامس }
$$
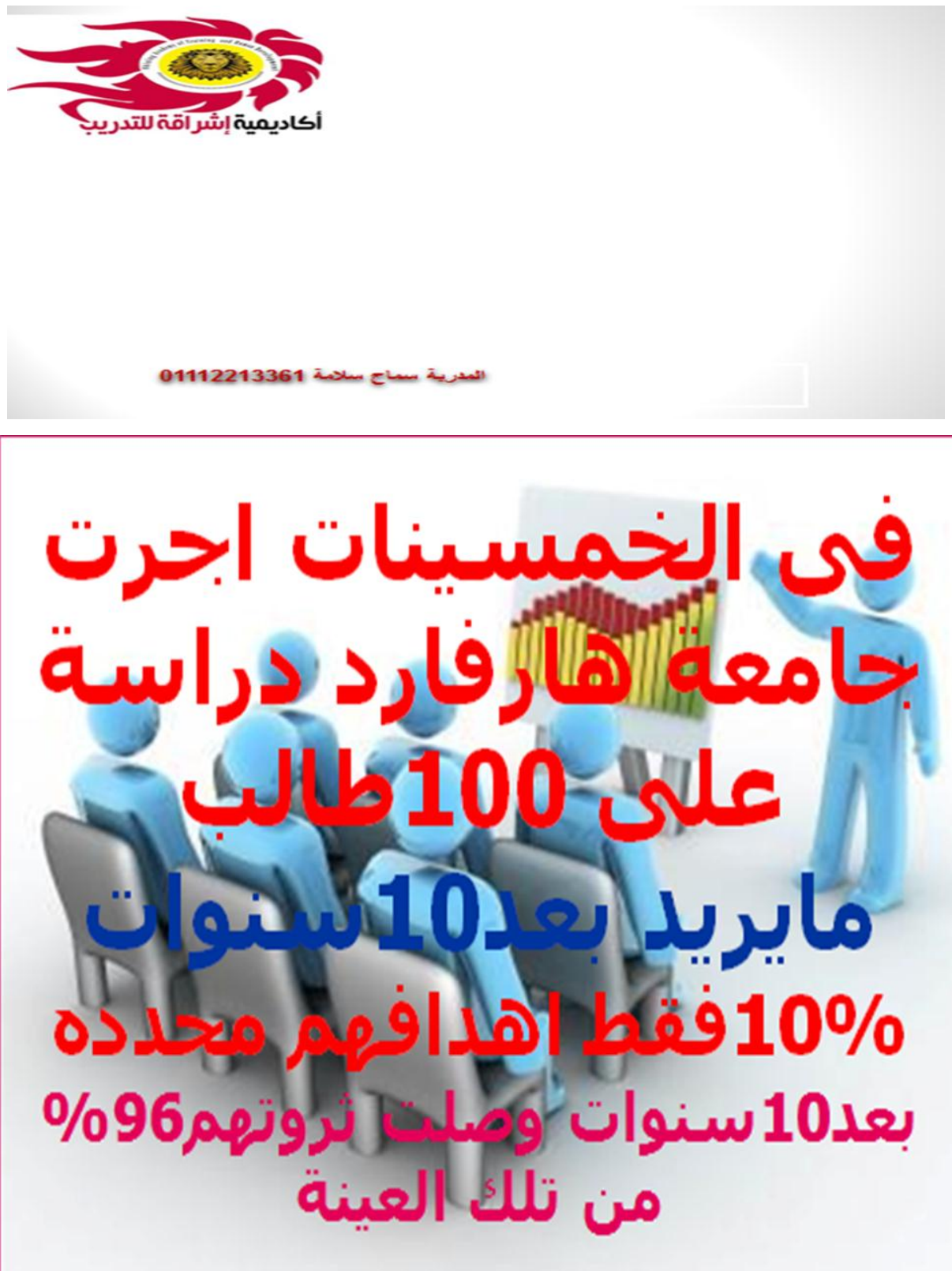

\section{9}

أوراق عمل وبموث المؤتهر الدولي الأول لمركز تنسية قدرات أعضاء هيئة

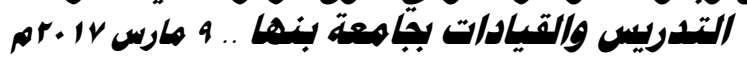




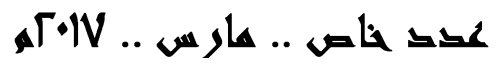

اجرت الجامعة دراسة على “. اطالب سالتهم من منكم يحلم الجميع رفع يده قالت من كتب احلامه وحلد اهدافه ـ 1\%زقط من قال نعم

بعلد • اسنوات بحثت عن الطلاب الذى تم عمل التجرية عليهم ودراسة النتائج وجلدة ان من كتب احلامه وحلد اهدافه هم من يقودون باقى
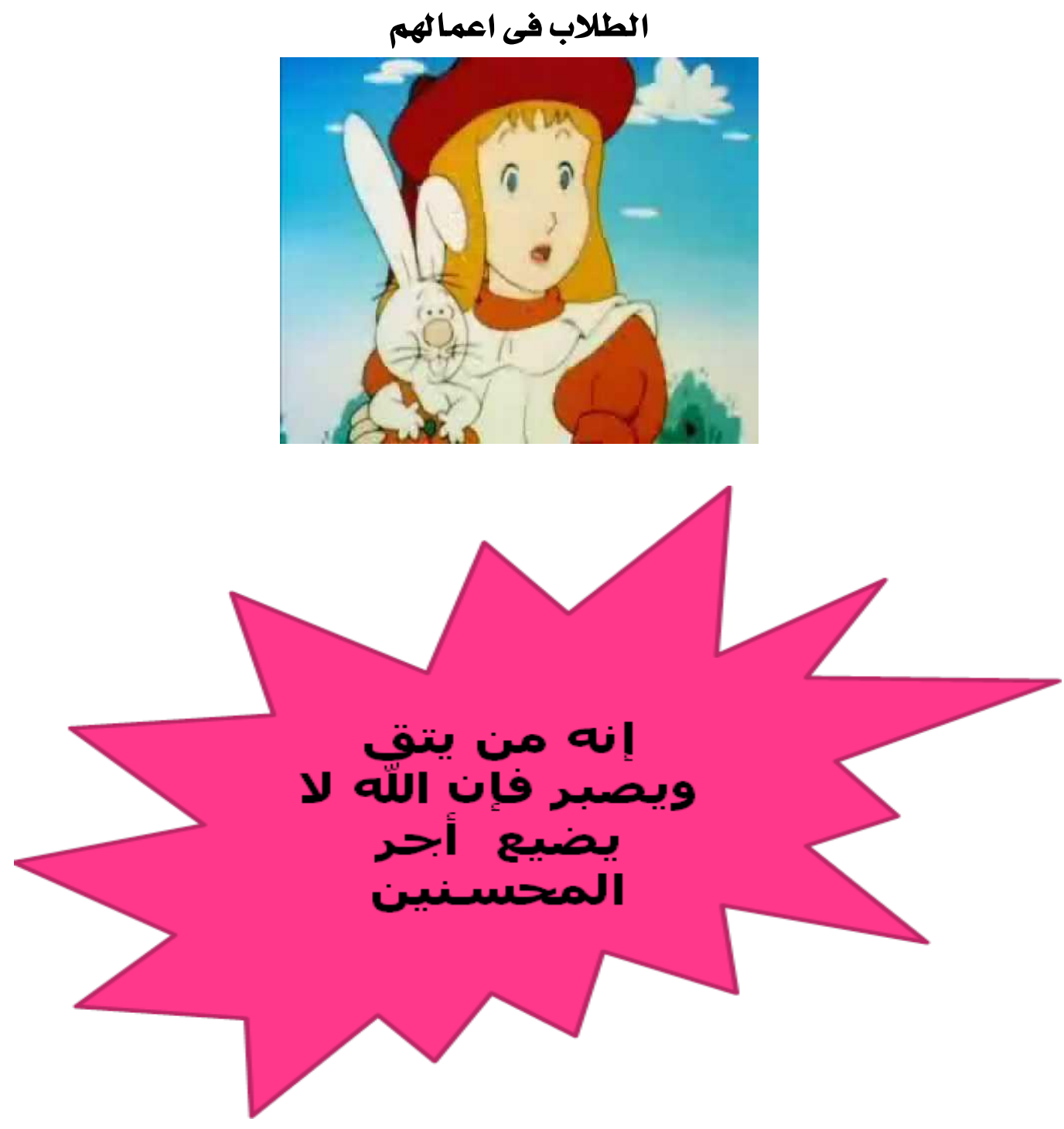

\section{1.}

أوراق عمل وبموث المؤتهر الدولي الأول لمركز تنسية تدرات أعضاء هيئة

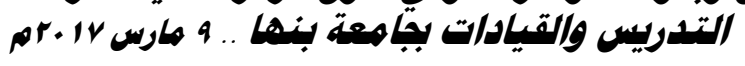




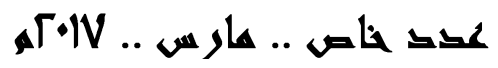

الس فى بلاد العجائب بتسال الارثب امشى من اى طريق سالها انتى

عاوزه تروحى فين قالت معرفش قال لها اذا الى طريق لايفرق معكا

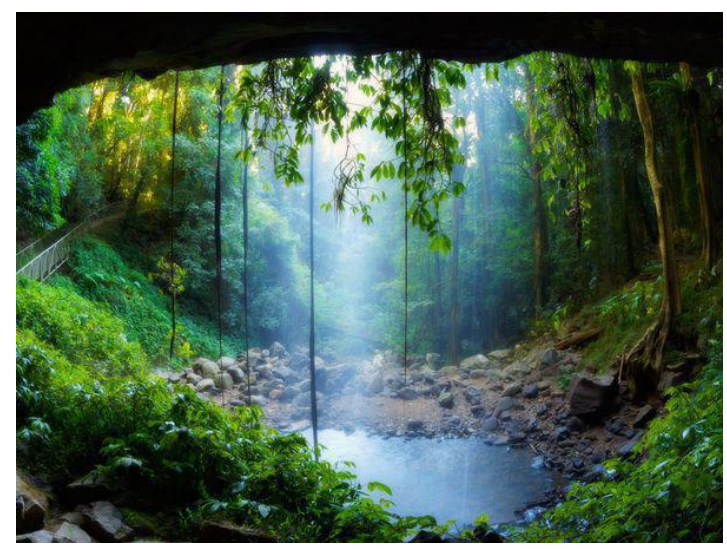

كان هنالك ملك يحكم جزيرة ومات الملك ويحث اهل الجزيرة عن ملك اخريحكمهم وكان من دستورالجزيرة ان يحكمها الملك خمس سنوات ثم ينفى الى الصحراء الجرداء المليئة بالافاعى .اقدم ثاب لمعاب للتقدم الى حكم الجزيرة لكن الجميع عارضه وخشى عليه ان ينفى ويفنى عمره فى الصحراء ويعل ان نصب الثاب ملك للجزيرة جمع كل الوزذاء وامرهم بتعمير الصحراء الجرداء وتحويلها اللى جنة خضراء وقبل خمس سنوات عمر الملك الصحراء وذهب اليها متوج جزاء لجهلده وحسن تخطيطه للمستقبل

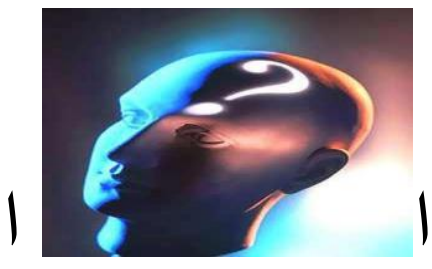

ماذا تتوقع ان تتعلم من هذه الدورة

\section{1}

أوراق عمل وبموث المؤتهر الدولي الأول لمركز تنسية تدرات أعضاء هيئة

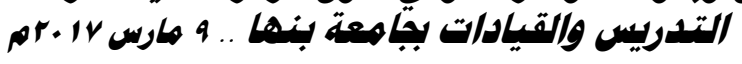




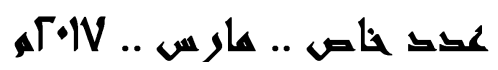

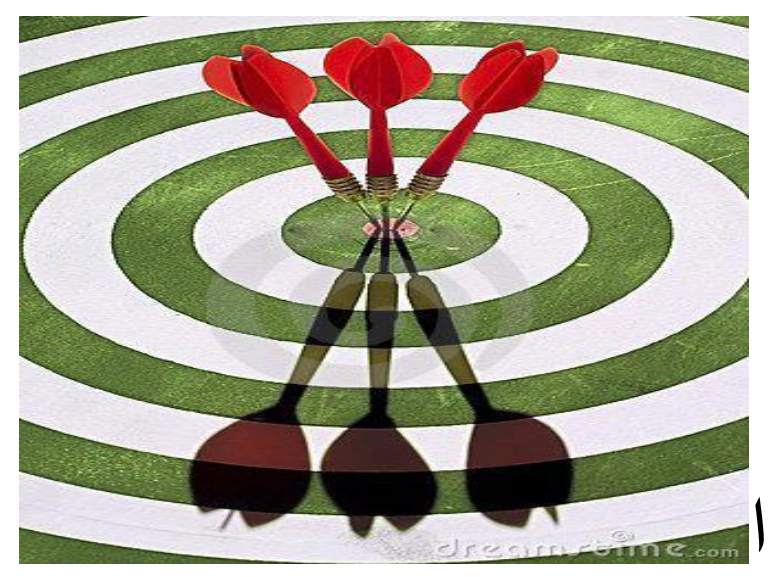

التدريب على كيفية وضع خطة استراتيجية تحتوى على الهدف والرؤية والرسالة

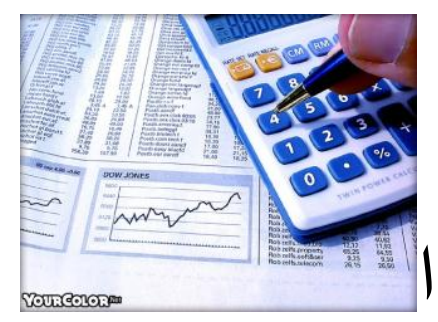

$$
\begin{aligned}
& \text { ما ستتعلمه فى النهاية }
\end{aligned}
$$

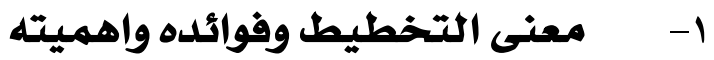

$$
\begin{aligned}
& \text { r }
\end{aligned}
$$

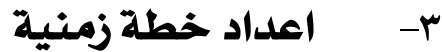

$$
\begin{aligned}
& \text { ع- وسيائل تنفيذ الخخطة }
\end{aligned}
$$

مهم ان تعرف ما تريل ... الاهم معرفة كيف تصل اليه

\section{$01 Y$}

أوراق عمل وبموث المؤتمسر الدولهي الأول لمركز تنسمية قدرات أعضاء هيئة

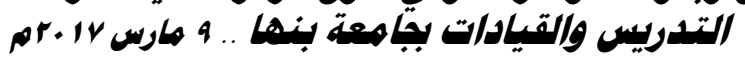




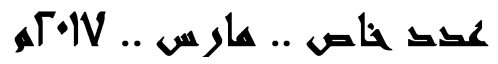

$$
\begin{aligned}
& \text { تصميم مستقبل فور } \\
& \text { مشرق فى } \\
& \text { الذهن الذوفر فوضع } \\
& \text { الخطوات الفهالة } \\
& \text { لتححقيقه الفهات }
\end{aligned}
$$
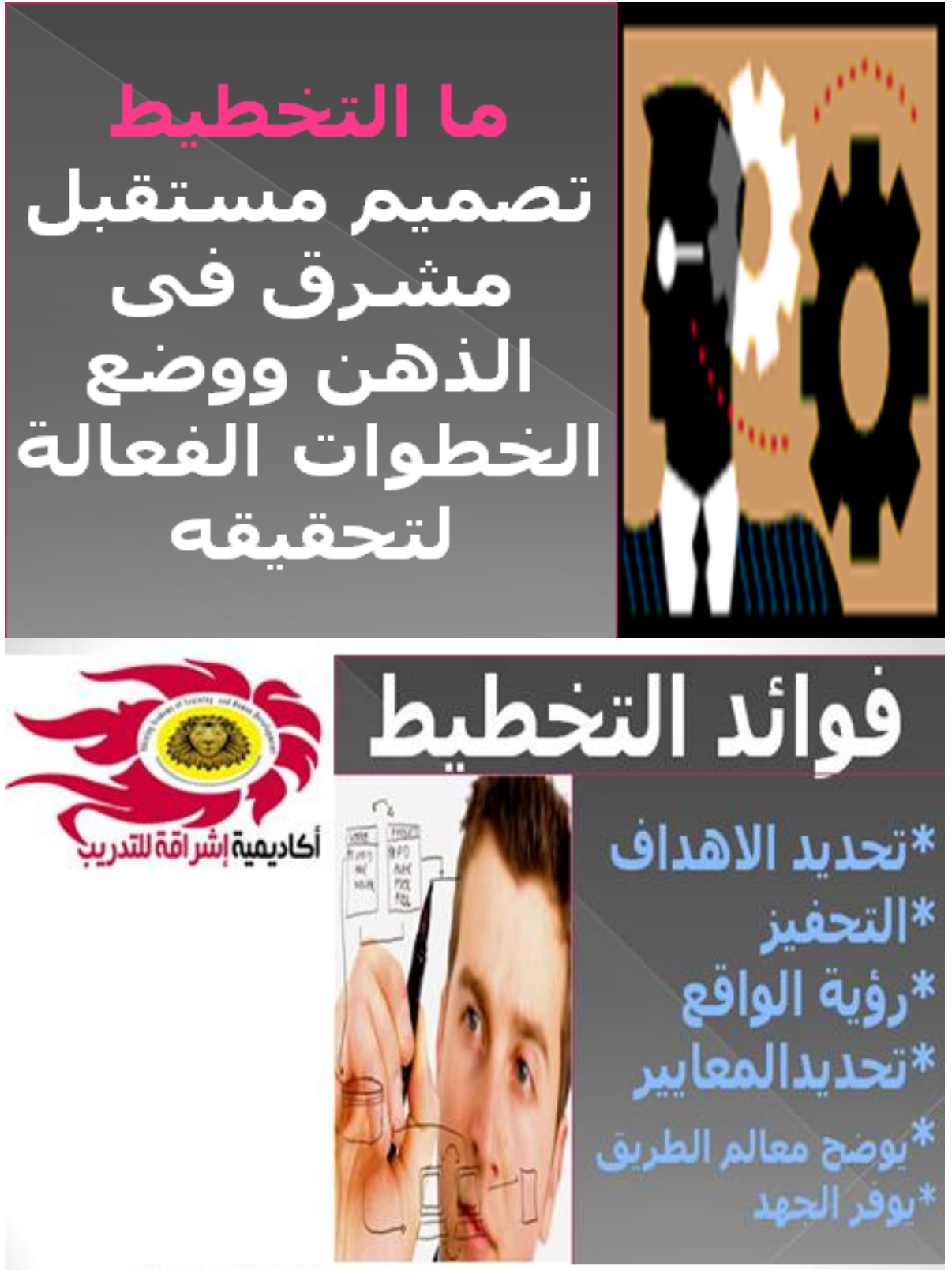

01112213361 العبرية سياع سلاند

*تحديد الاهداف

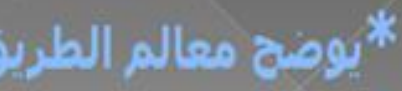

10기 $g_{0 *}^{*}$ 
لحق خاص .. عار س .. VIיזم

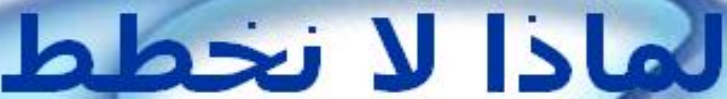

*معهوم سلبى عن التخطيط *عدم استطاعة رسم خطم *عدم معرفة الإولوياتة *الخوف من اللمجرهول *عدم الثباوفوالهبر



أوراق عهل وبموث المؤتير الدولي الأول لمركز تنسية قدرات أعضاء هيئة التدريس والقيادات بجاهعة بنها .. 9 هارس VI . بمم 
عלכ خاص .. هار س. .. VIיזم,

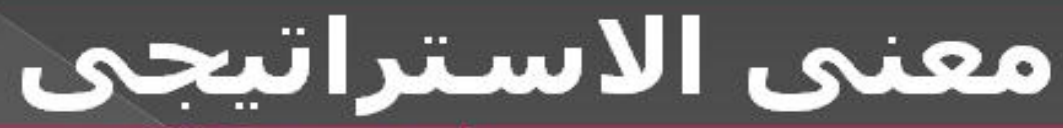

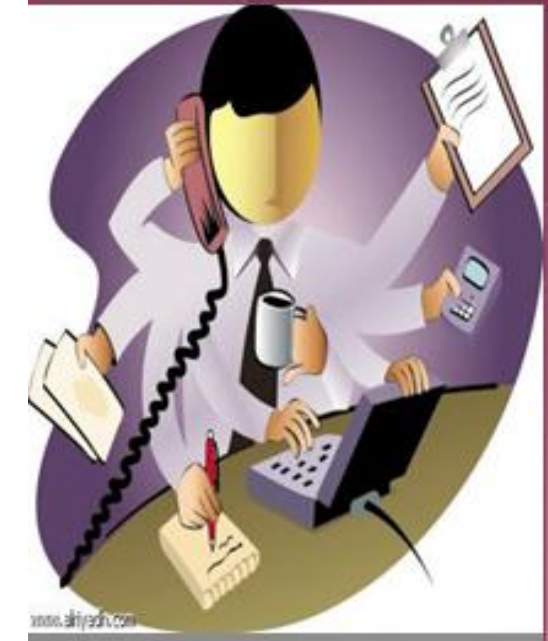

*المدى البعيد *الاهمية البمدية

*ادارة الضغوط

*التنافس الض * التوقع

matipartes:

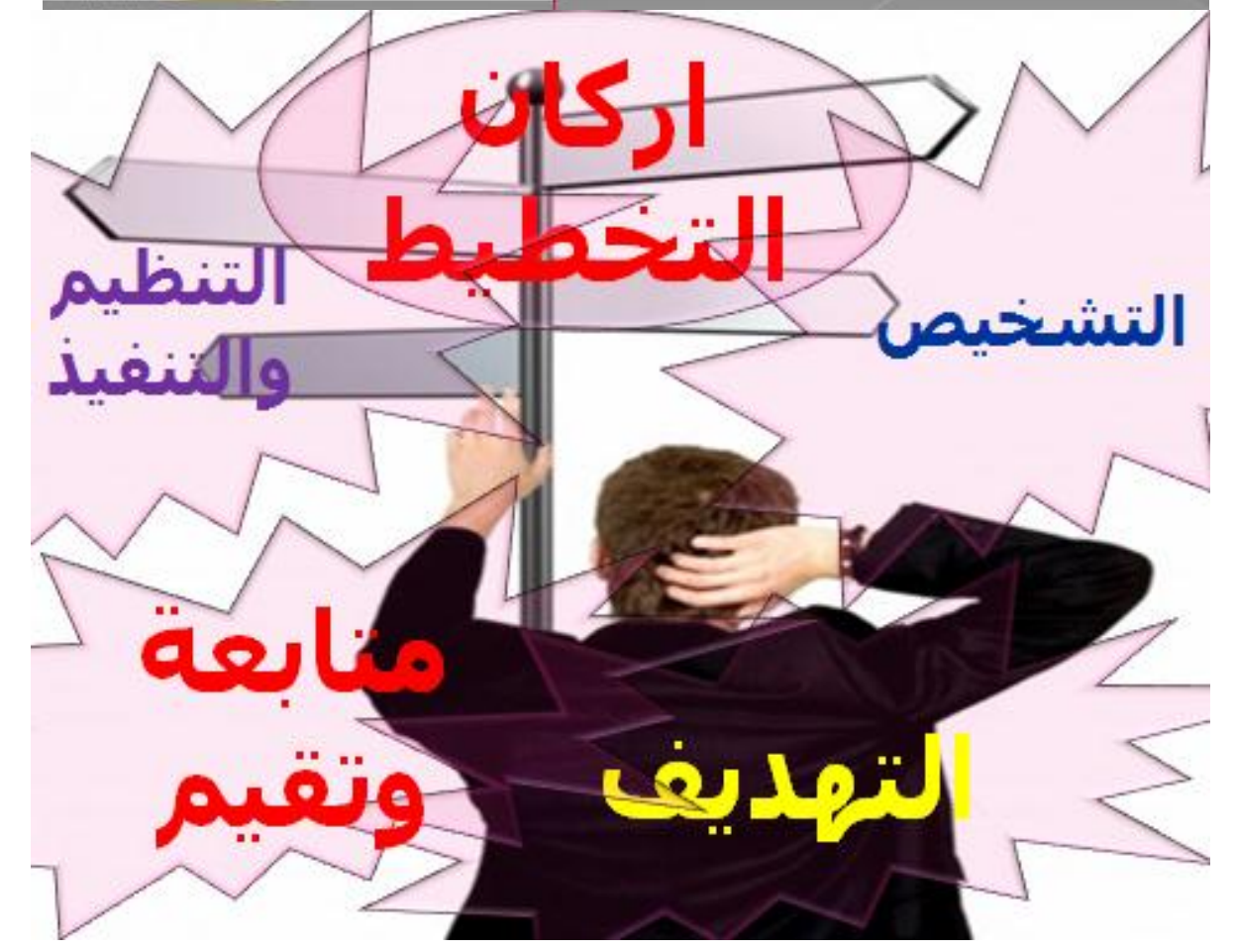

010

أوراق عمل وبموث المؤتهر الدولي الأول لمركز تنسية تدرات أعضاء هيئة

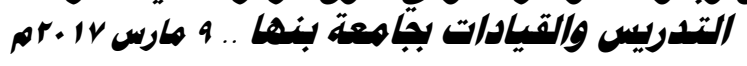




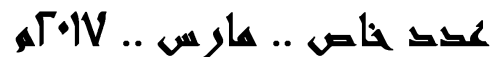

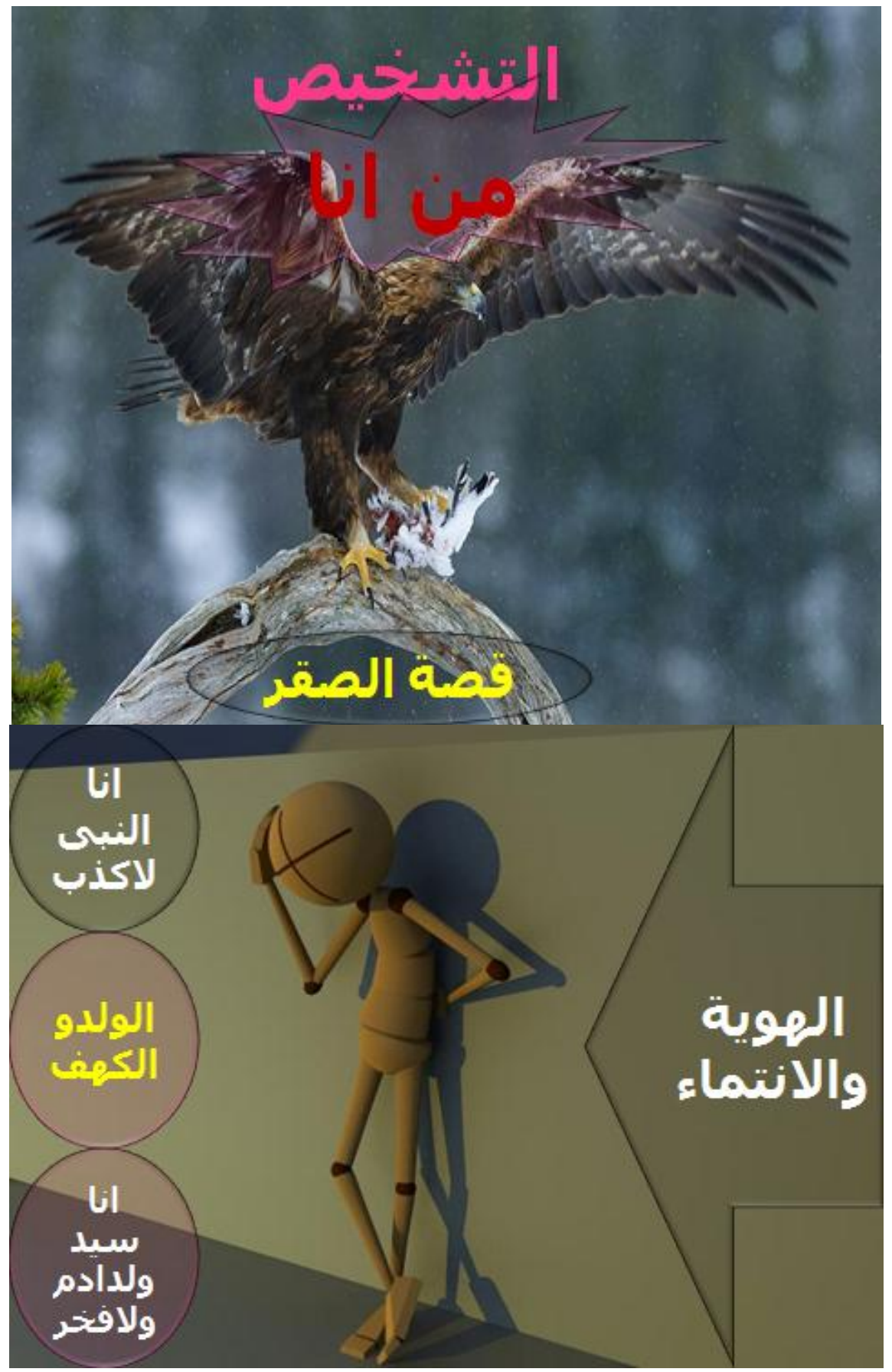

أوراق عمل وبموث المؤتهر الدولي الأول لمركز تنسية قدرات أعضاء هيئة

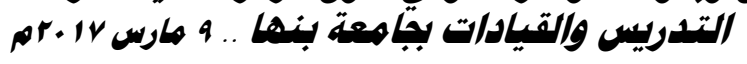




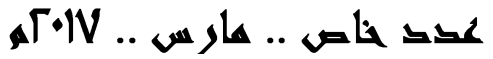

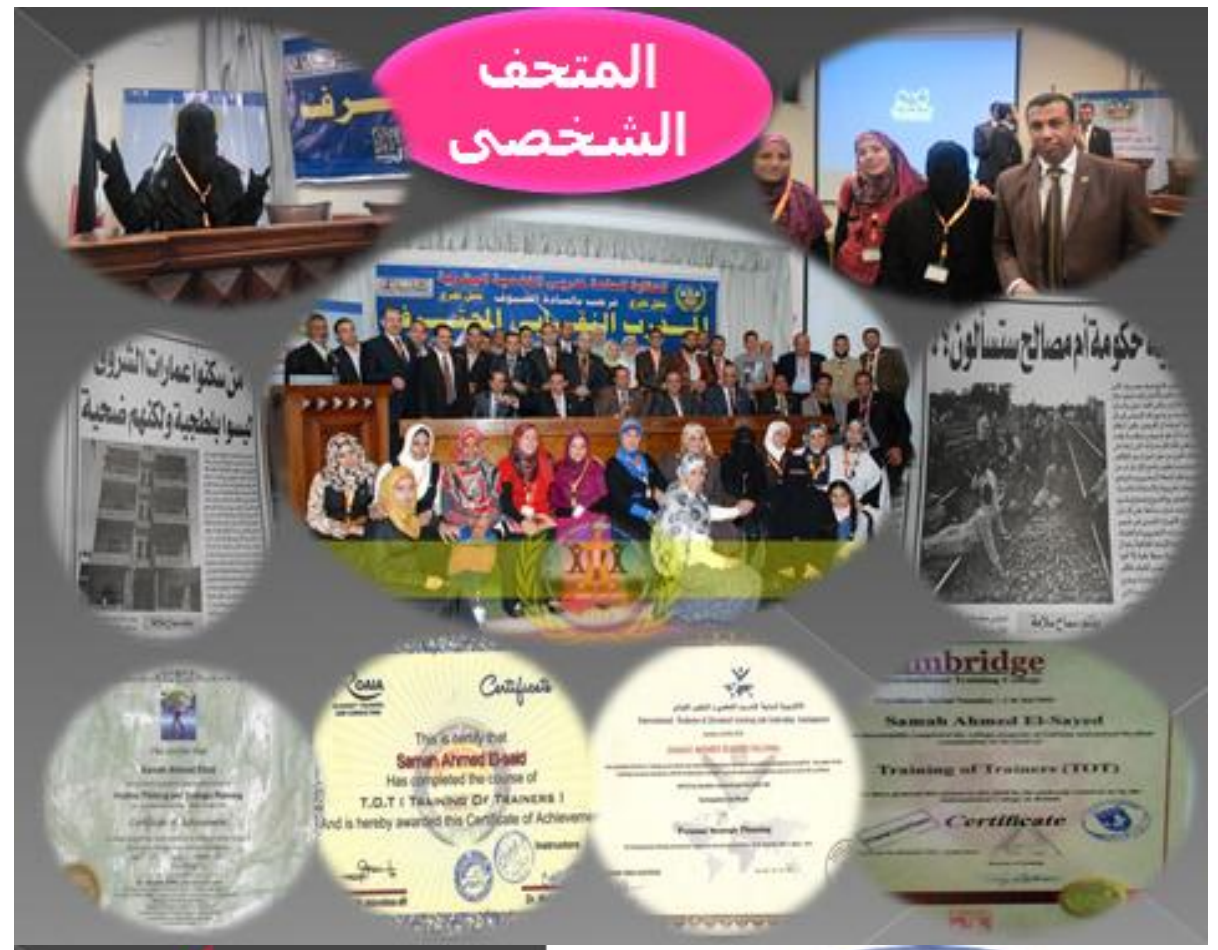

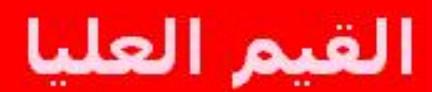

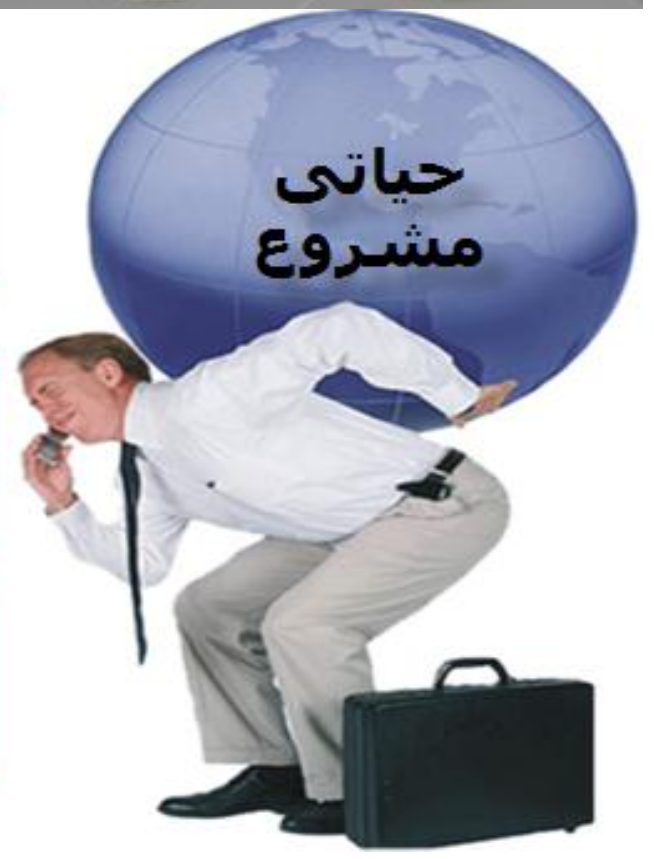

الاعتقاد الذاتى

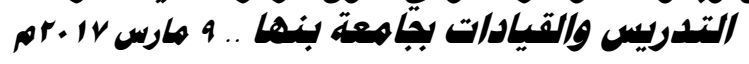


عقد خاص .. عار س .. VIיזم,
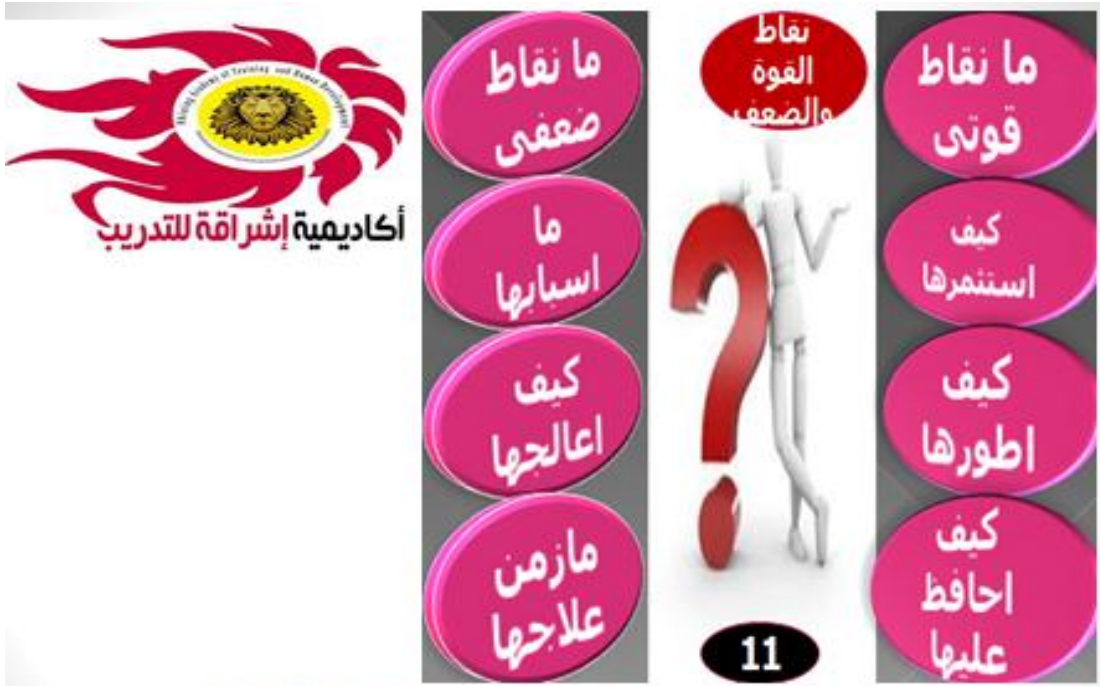

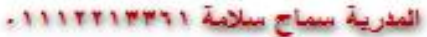

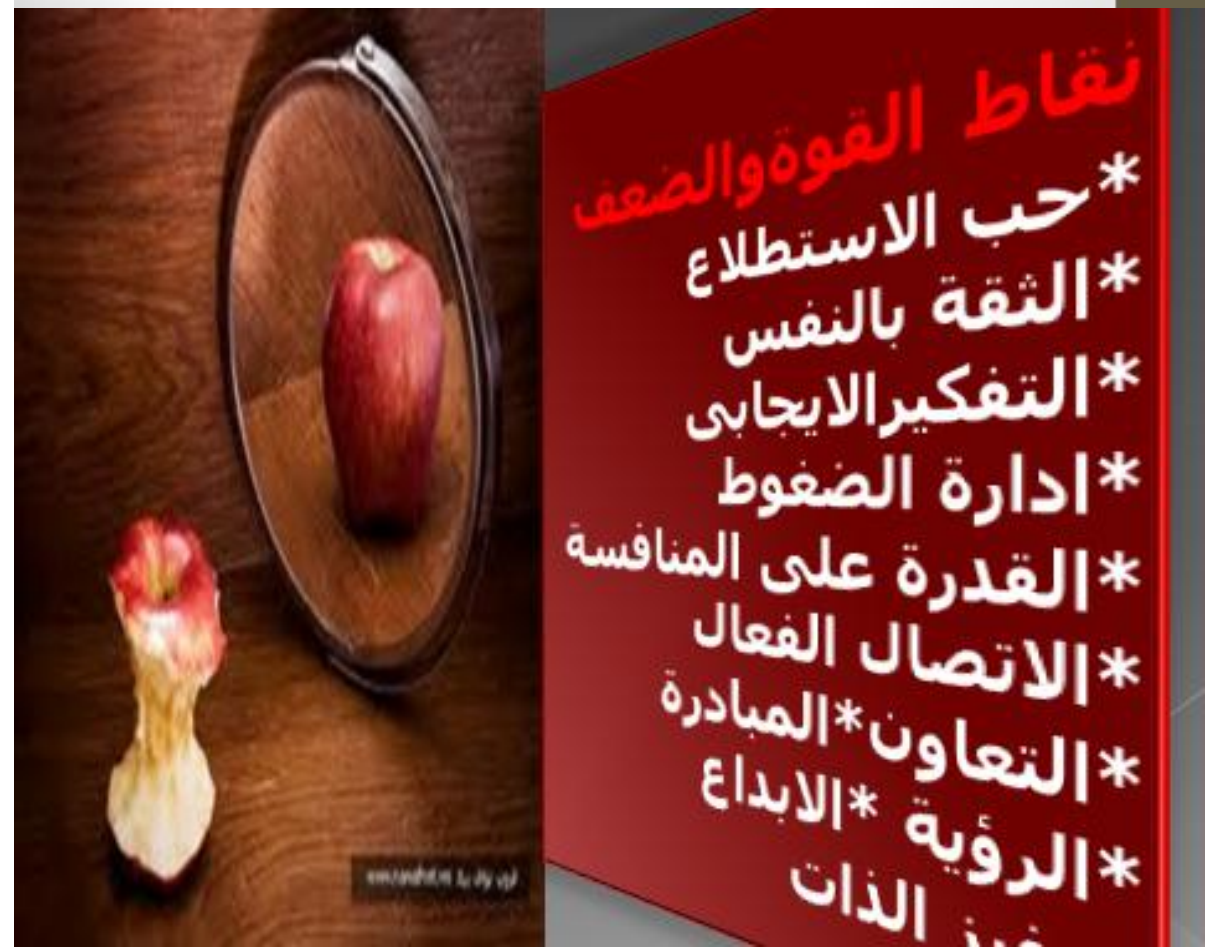




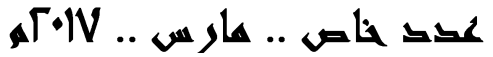
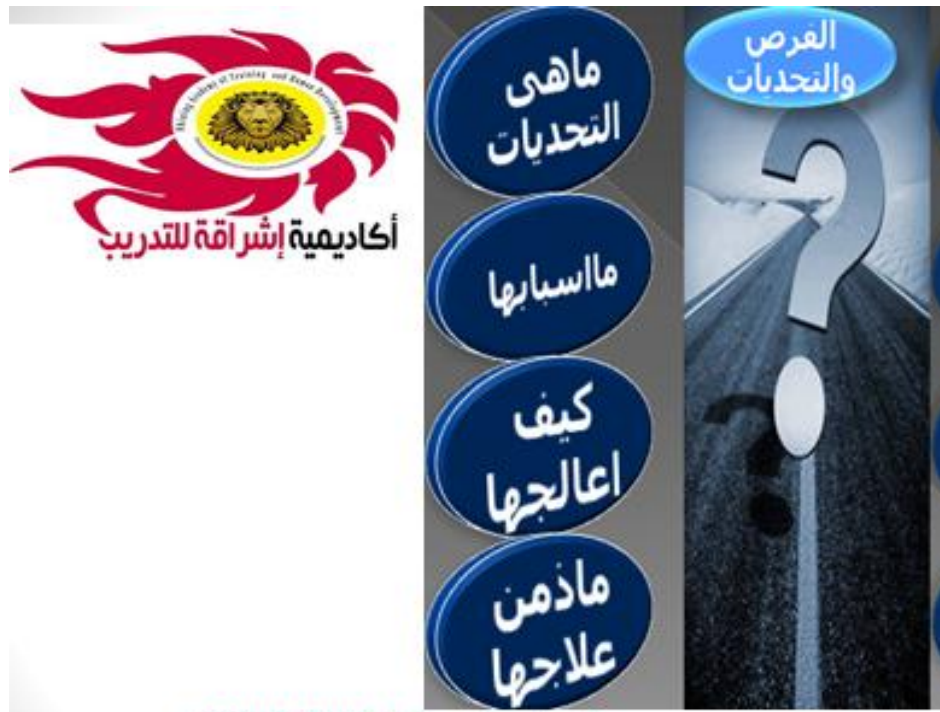

งค่อ

|l

5ل

ens

|

bin

ins

|rivi|

ins

bibl

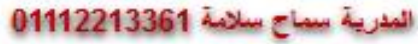

علئ

الفرص والتحديات

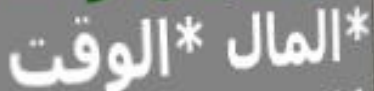
*اسرة*القانون *المن

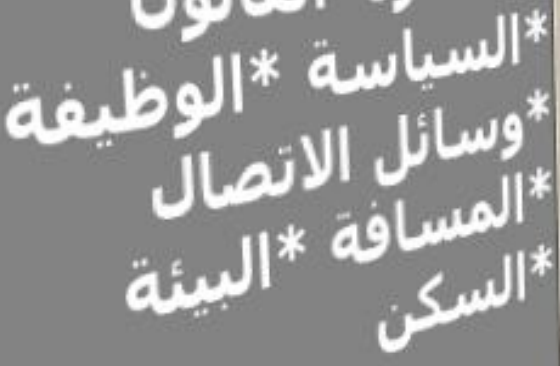

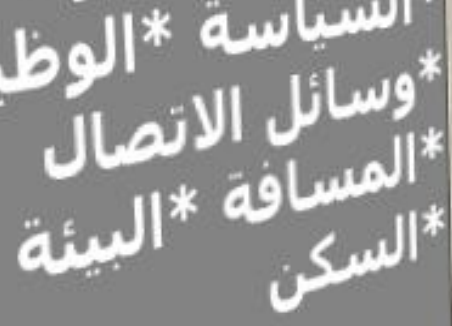

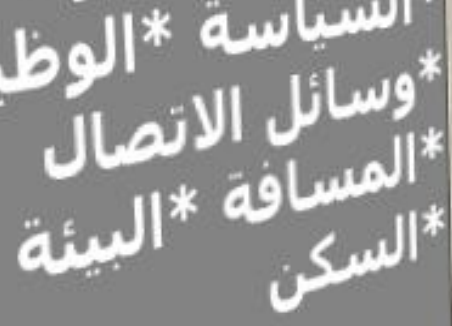

\section{S}

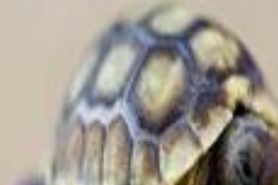

019

أوراق عهل وبموث المؤتير الدولي الأول لمركز تنسية قدرات أعضاء هيئة

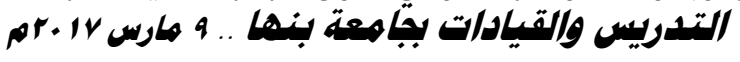


عقد خاص .. عار س .. VIV مa

\section{خطة التغيير}

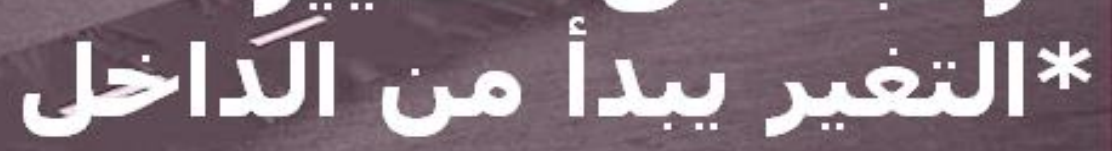

$$
\text { *انت المسئولفئ }
$$
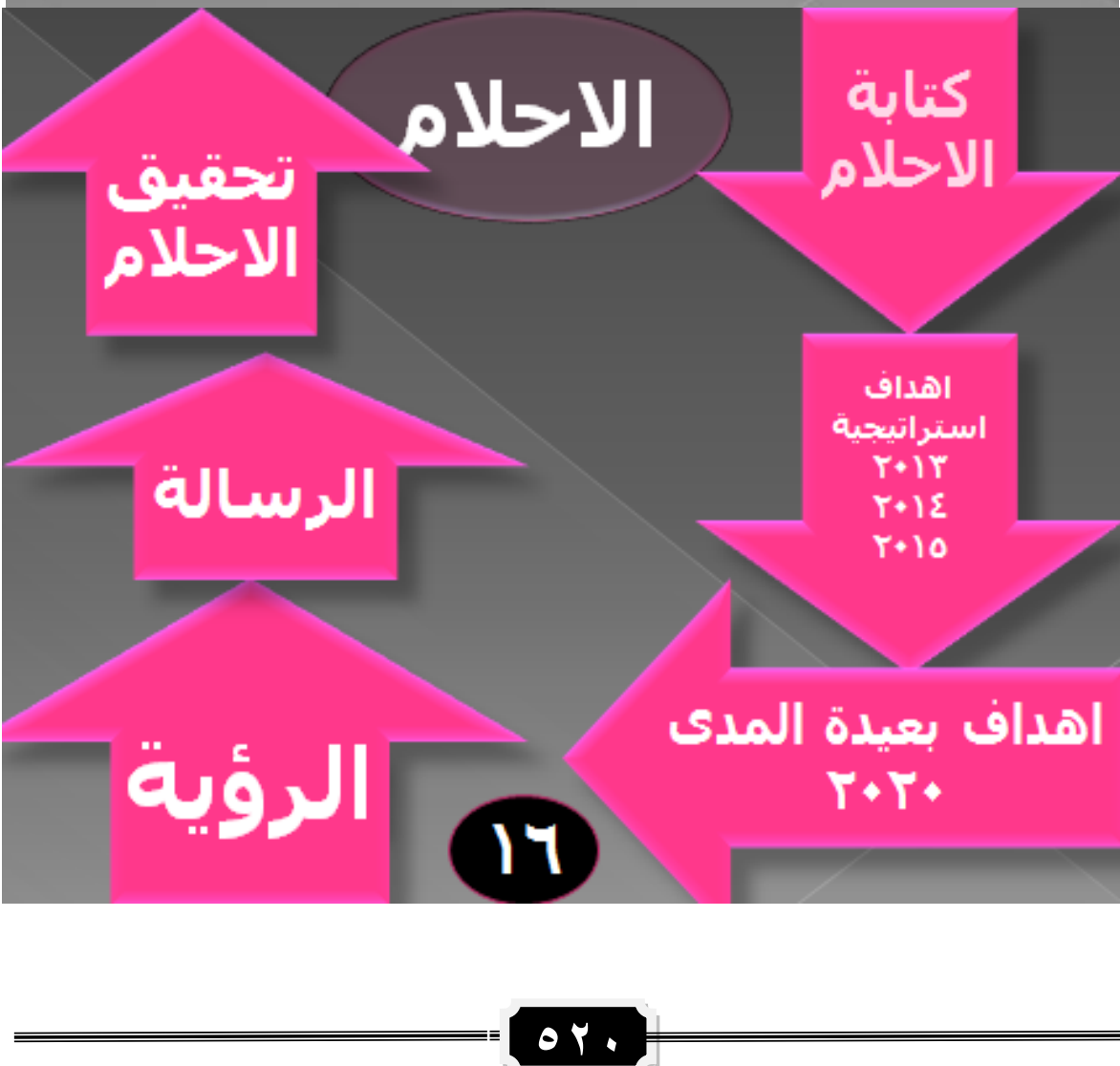

أوراق عمل وبموث المؤتهر الدولي الأول لمركز تنسية قدرات أعضاء هيئة

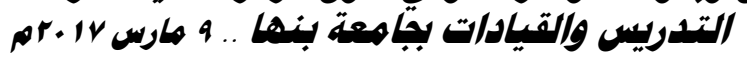


كقد خاص .. هار س .. VIיTم
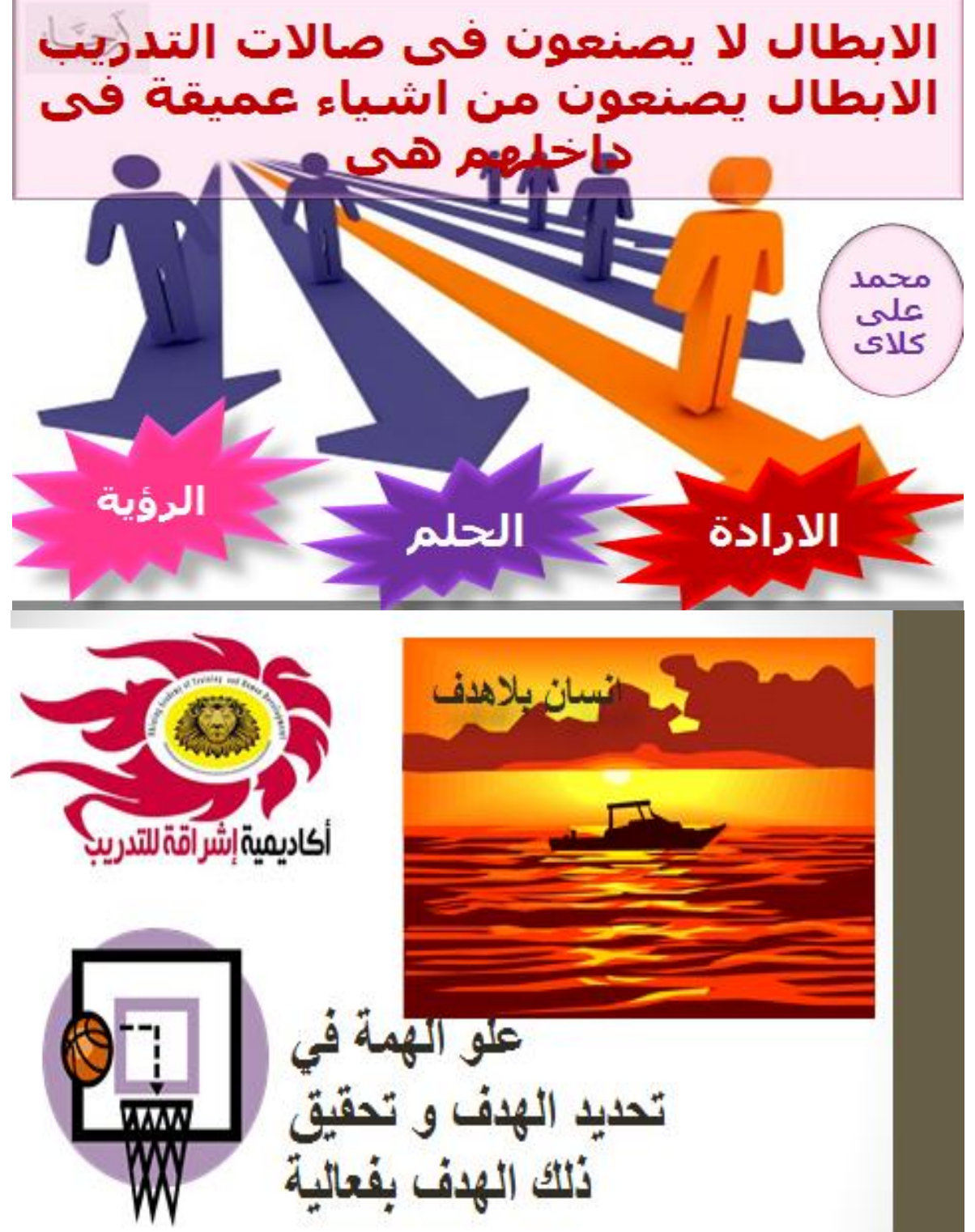

علو الهمبة في

تحدي الهرف و تحقيث

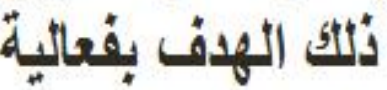

01112213361 الثدرية سيفاع سلادية

\section{OY}

أوراق عمل وبموث المؤتهـر الدولهي الأول لمركز تنسمية قدرات أعضاء هيئة

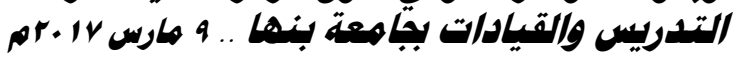




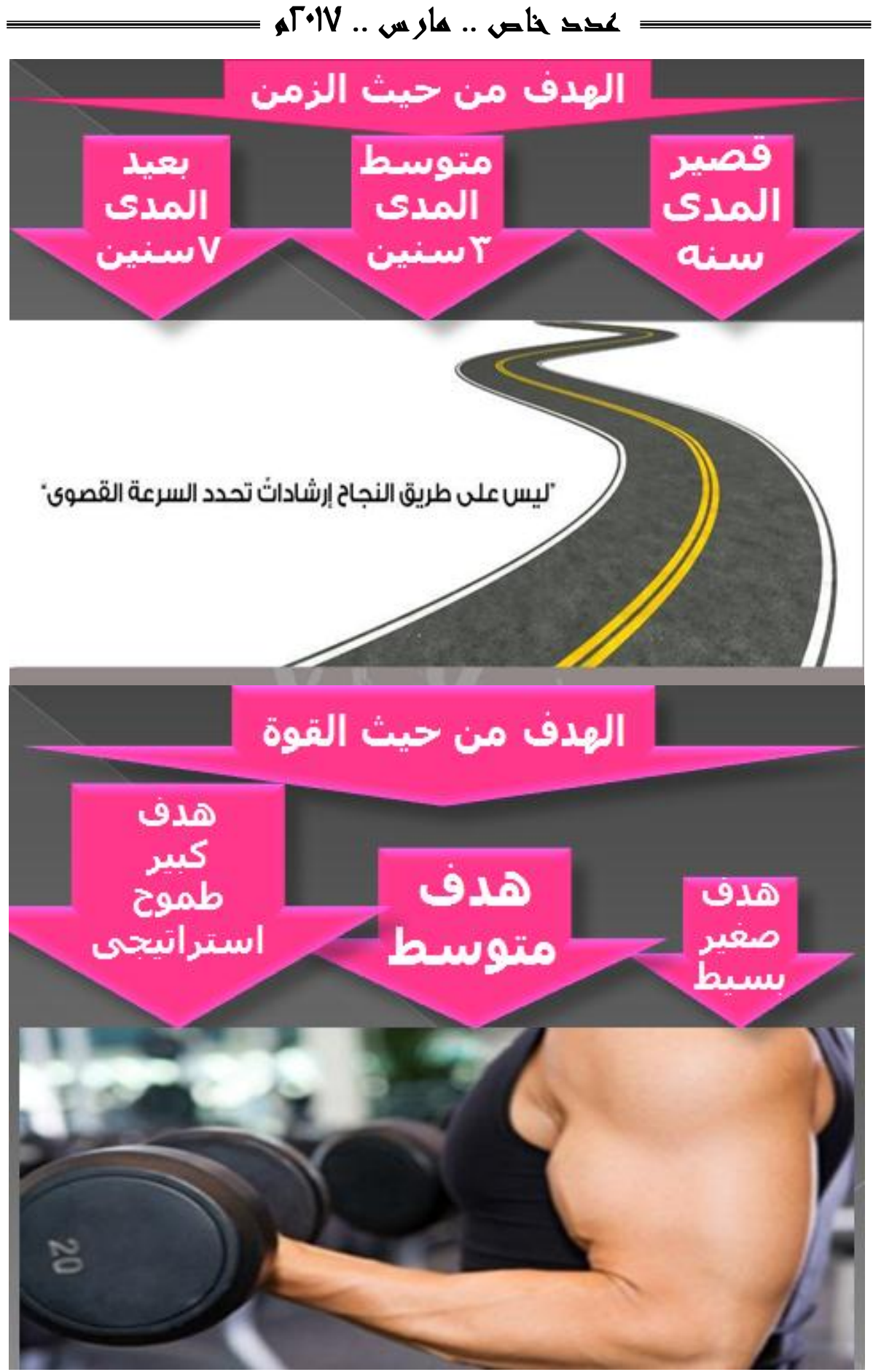
التدربس والقيادات بقّاهعة بنها .. q هارس v1 .rم 
عقد خاص .. عار س. .. VIיזم

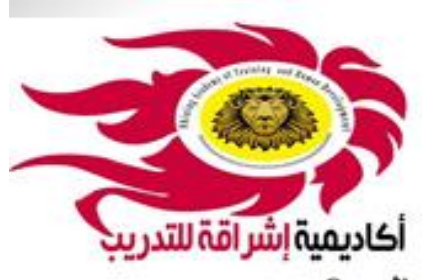

• •

• أين أريد أن أكون ؟ و ما هي طموحاتي المستقبلية ؟

• كيف سأبلغ تلك المرحلة ؟ ما هي الوسائل المطلوبة ؟

• كيف أعرف أنني حققت ما أصبو إليه ؟

01112213361 المدرية سياع سلاية

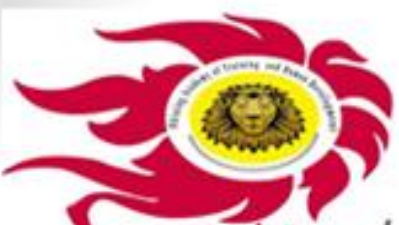

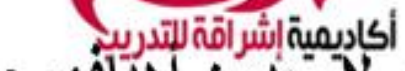

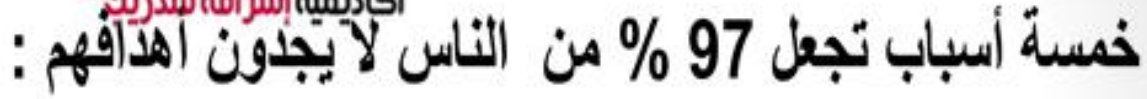

$$
\begin{aligned}
& \text { 1- الخوف . } \\
& \text { 2- صورة الأات الخاطئة . } \\
& \text { 3- } \\
& \text { 4- الاعتقاد و الإيمان السلبي. }
\end{aligned}
$$

\section{OYY}

أوراق عمل وبموث المؤتهر الدولي الأول لمركز تنسية تدرات أعضاء هيئة

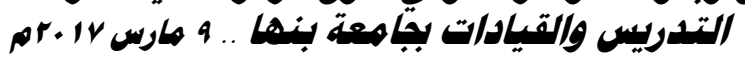




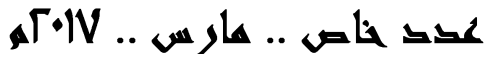

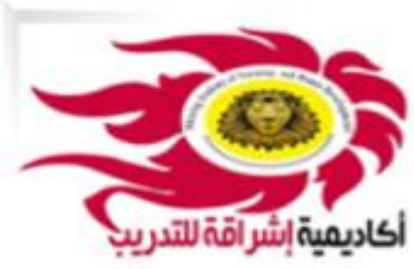

$$
\text { ـ... - الرسالة }
$$

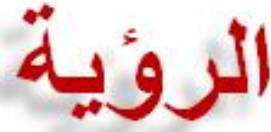

01112213361 ish ches

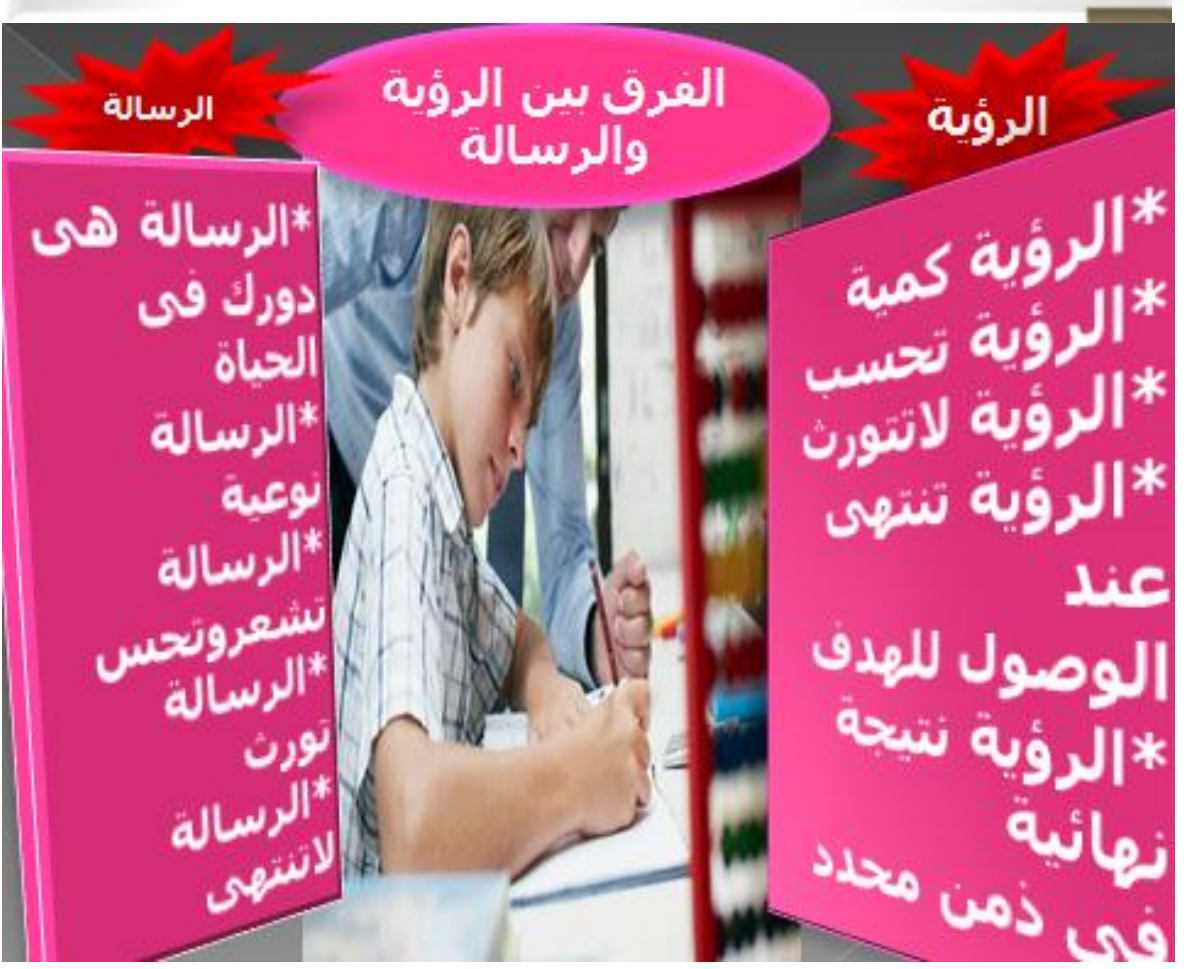


كבق خاص .. هار س .. VIיזم

\section{من انـا}

أكاديمية إشراقةقللتدريبي

- إنتي أحقق فايتي الأسساسية في الحياة من

خلال مشاركتي في صنّع عالم ممتلمئ بالإثـارة

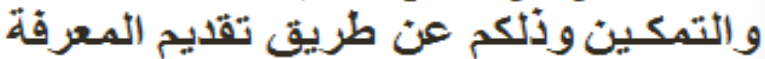

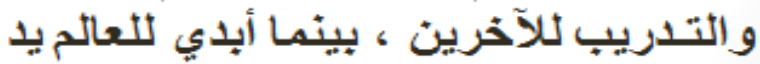

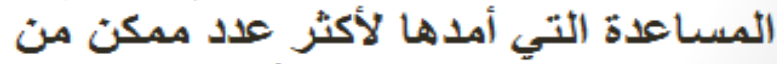

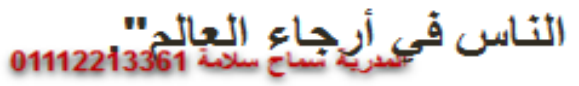

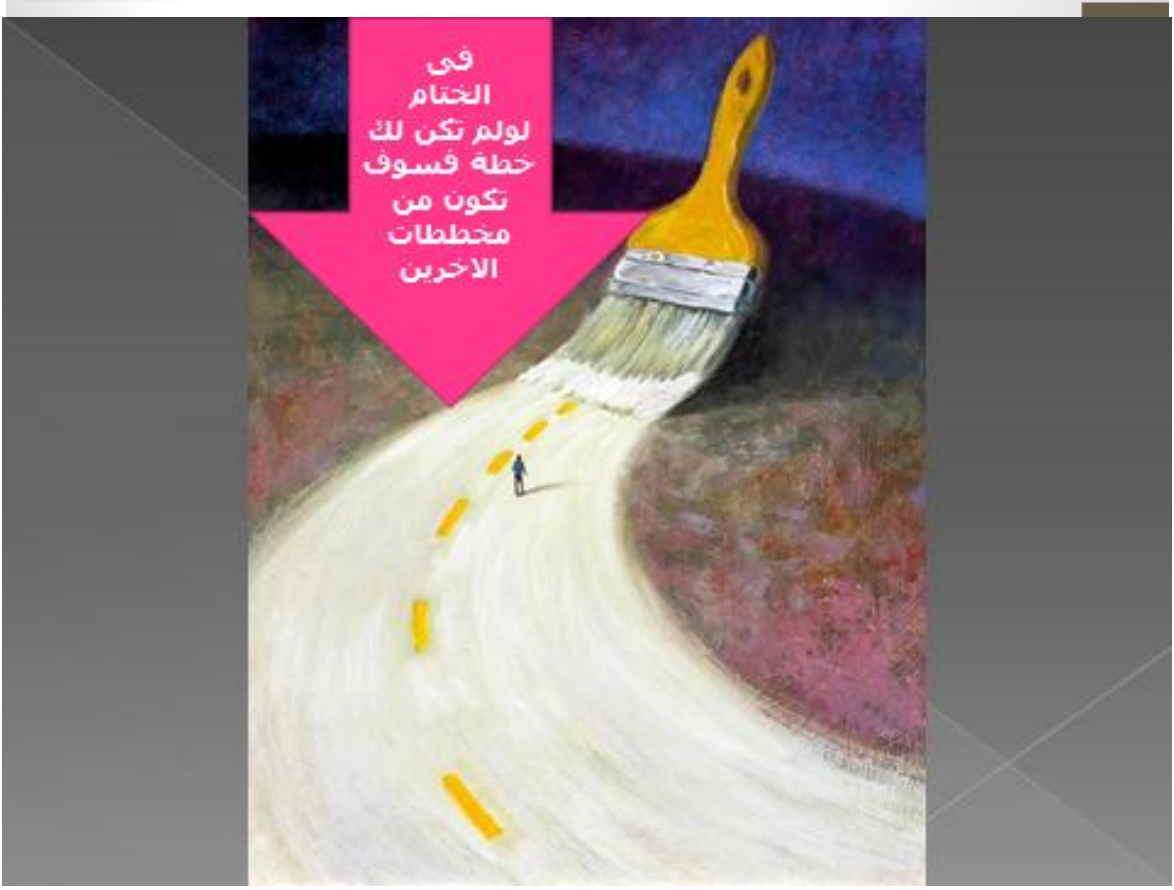

楼溇溇洸

\section{OYO}

أوراق عمل وبموث الموتمهر الدولسي الأول لمركز تنسمية قدرات أعضاء هيئة

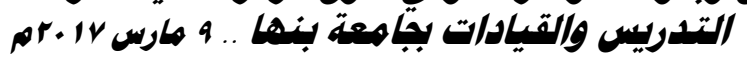

